\title{
CASTRO, Celso; LEIRNER, Piero (org.). Antropologia dos Militares: Reflexões sobre pesquisas de campo. Rio de Janeiro: Editora FGV, 2009. 242 p.
}

Aline Fonseca Iubel A coletânea organizada pelos dois pioneiros nos estudos antropológicos dos militares

UFSCAR brasileiros reúne artigos de pesquisadores de várias áreas das Ciências Humanas versando sobre suas experiências de pesquisa em instituições militares. Além daqueles que se formaram ou estão em formação na antropologia, completam o livro uma historiadora, uma cientista política e uma psicóloga. Em comum a todos os autores está a pesquisa etnográfica e o recurso à teoria antropológica. A reflexão sobre o método característico da antropologia - a pesquisa de campo com observação participante -, suas condições de utilização e rendimento neste contexto determinado é o fio que conduz o leitor por uma espécie de viagem para dentro de diversas esferas da vida militar. Aliás, ver e mostrar o interior e o cotidiano de militares e dos que os rodeiam é um dos avanços conquistados com a entrada dos estudos antropológicos no universo militar, uma área que durante décadas foi dominada por cientistas políticos, sociólogos e historiadores que enfatizavam as intervenções militares na política ou se dedicavam a pensar a transição do regime militar para a democracia.

Com Celso Castro e Piero Leirner, ainda nos anos 1990, iniciou-se um processo de superação de uma visão "externa" e "exotizante" em relação aos militares e, passou-se a compreender melhor como se constrói a identidade militar e como se estrutura sua visão de mundo. Eles deram o ponta pé inicial para uma série de pesquisas que vêm se desenvolvendo ao longo dos últimos dez anos - movimento do qual o livro é testemunha - e que continuam a enriquecer o conhecimento etnográfico não só dos momentos extraordinários da vida militar, mas, principalmente, de sua rotina. O objetivo do livro é explicitamente refletir sobre as experiências e trajetórias pessoais dos pesquisadores em suas relações com seus objetos e campos de pesquisa, mas, nem por isso ele deixa de contribuir etnograficamente a esta linha de pesquisa, ainda em formação, que é a antropologia dos militares, findada a leitura, 
que interessa não somente pesquisadores que se dedicam ao estudo de militares, mas também a antropólogos atuantes em outros temas, bem como a pesquisadores de outras disciplinas que buscam a pesquisa etnográfica como metodologia de pesquisa.

O exercício proposto pelo livro, de refletir sobre algo que normalmente permanece inaudito - as trajetórias pessoais que cada pesquisador delineou com seus objetos e campos de pesquisa - fica ainda mais interessante na medida em que as experiências dos autores revelam características fundamentais da identidade e da estrutura militar. A necessidade de autorização formal é algo citado pela quase maioria dos autores, com exceção de Juliana Cavilha e Fernanda Chinelli. Mas, algo também corrente nesse processo de autorização formal é a morosidade. Castro relata que, apesar dos cuidados na redação da carta de solicitação de autorização e dos contatos estabelecidos a partir do acionamento de seu pertencimento a uma "família militar" (seu pai era militar), na tentativa de diminuir a distância simbólica existente entre ele e seus interlocutores de pesquisa, a autorização para a pesquisa na Academia Militar das Agulhas Negras (Aman) não demorou menos que dois meses. A mesma dificuldade foi vivida por Aline Prado Atassio que, para realizar sua pesquisa na Escola de Sargento de Armas, viu-se obrigada a reelaborar diversas vezes seu projeto até que, após um ano de espera angustiante, concedida a autorização, ela tivesse que correr para cumprir os prazos da proposta aprovada. A morosidade chega inclusive a casos extremos, como o de Leirner, que freqüentou durante dois anos a Escola de Comando e Estado-Maior do Exército na espera de uma autorização que nunca foi concedida. O importante é que em nenhum dos casos a morosidade ou as dificuldades iniciais foram empecilhos definitivos para as pesquisas, muitas vezes transformaram-se em dados etnográficos importantes das mesmas.

Para além da demora nos processos de autorização, depois de iniciadas as pesquisas em instituições militares foram comuns situações nas quais os pesquisadores se viram "colocados à prova", "testados", "dissuadidos", "controlados" ou "vigiados". Leirner ressalta a constante tentativa de controle dos etnógrafos por parte dos militares, grupo que têm de antemão regras explícitas e protocolos que tanto servem para suas próprias condutas quanto para o que deve ser a conduta dos outros, donde que, nas pesquisas etnográficas com militares parece haver pelo menos duas inversões: a) do olhar antropológico: segundo Leirner, "tudo se passa como se aquilo que o antropólogo procura implicitamente entre seus nativos aqui estivesse colocado de maneira explícita" (p. 32), como se a prática de certa maneira estivesse dada na teoria; b) do fluxo de informação entre antropólogos e militares: Quem interroga quem? Quem é o informante? São novas questões e problemas que surgem com esse novo objeto. Essa forma de "controle" ficou explícita nos mais diversos convites que Leirner recebeu para trabalhar para os militares. Cristina Rodrigues da Silva, que realizou pesquisas sobre gênero e família em duas instituições de formação inicial de oficiais - a Academia da Força Aérea (AFA), em Pirassununga e a Aman, em Resende -, também relata que já uma constante vigilância e fiscalização da corporação sobre os métodos empregados pelo antropólogo para realizar a etnografia, o que implica num intenso processo de negociação entre o pesquisador e o pesquisado e demonstra uma importante característica militar: operar com extrema organização e previsibilidade das atividades. A mesma 
sensação de constante observação é citada por Emília Takahashi, que teve as portas abertas para a pesquisa pelo fato de ser professora de psicologia na AFA. Essa proximidade, no entanto, teve para ela duas faces, se por um lado facilitou seu acesso à instituição, sobretudo às áreas restritas à maioria dos civis, por outro, ela viu-se obrigada a lidar com a curiosidade intensa e por vezes inconveniente de alguns colegas, com a falta de privacidade para trabalhar com o material de pesquisa durante o expediente na academia e com os freqüentes comentários e sugestões que Ihe eram dadas. Adriana Barreto de Souza, em suas experiências de pesquisa em arquivos militares passou por alguns "testes de resistência", mas conseguiu ser bem recebida através da construção de uma relação cotidiana e efetiva de trabalho, pautado em valores aproximaram os modos de operar da organização militar e do mundo acadêmico: o respeito e o cumprimento das normas, no caso da pesquisadora, de ambos os universos.

Outra situação recorrente foram as tentativas de "dissuasão", geralmente decorrentes da preocupação que a corporação militar tem com sua imagem. Alexandre Colli de Souza conta que muitas vezes, ainda na fase de tentativas de conseguir autorização para a realização de pesquisa de campo, sentiu que os militares tentavam "despistá-lo", remetendo-o incontáveis vezes a instâncias diferentes. A preocupação com a imagem da corporação foi algo presente também durante a pesquisa de Lauriani Porto Albertini sobre as relações civis-militares em diversas instituições do Exército Brasileiro. A única autora que não teve dificuldades para sua entrada em campo foi vista e "cooptada" como uma espécie de "amiga do Exército", um "canal para dar voz à Força como parte da construção de uma nova e boa imagem do Exército" (p. 85), segundo um oficial do Centro de Comunicação Social do Exército. Fernanda Chinelli, que desenvolveu pesquisas não na caserna, mas nas casas de militares, tomando como interlocutoras as esposas destes percebeu que a casa não era totalmente alheia às formalidades da instituição militar e que as mulheres estavam também comprometidas com as carreiras de seus maridos e com a imagem do Exército. Isto já anuncia uma outra característica fundamental, que é a transmissão do espírito militar a esferas pessoais e familiares da vida dos oficiais e de seus próximos, que, segundo Chinelli, minimizam as tensões que ameaçariam colocar em risco a adesão incondicional ao espírito militar.

Quanto a isto, outra característica invariavelmente citada pelos autores do livro é a existência de pelo menos duas modulações, freqüentemente imbricadas, que operam logicamente e são estruturantes do universo dos militares: "civil/militar" e "amigo/inimigo". Quanto à primeira, conforme sugeriu acima Chinelli, mas também Castro, a identidade militar é totalizante: tornar-se militar é deixar de ser civil e, depois de militar, não se volta a ser civil, no máximo, transita-se à paisana neste mundo. Esse "tornar-se militar" é observado principalmente pelos pesquisadores dedicados às instituições de formação de oficiais, mas também não escapou ao olhar atento de Juliana Cavilha, que construiu uma etnografia a partir de entrevistas com seis oficiais militares reformados e da observação de rituais e solenidades realizados em um Batalhão de Infantaria de Florianópolis. A vivência com militares da ativa e reformados, dentro e fora do batalhão, lhe possibilitou perceber as normas que regem o controle do corpo e a uniformização dos gestos como algo que imprime ou tatua um ideal de masculinidade baseado na imagem do guerreiro, que não é abandonado nem mesmo com a aposentadoria. 
A única experiência estrangeira do volume é trazida por Máximo Badaró e é sugestiva quanto àquelas duas modulações anteriormente apontadas. Badaró realizou pesquisa no Colégio Militar da Nação (CMN), única academia de formação inicial de oficiais do Exército argentino, e notou que, para que se construa uma "distância justa" que possibilite o sucesso da pesquisa, aquelas modulações devem ser rigorosamente observadas. Foi por isso que o pesquisador passou a adotar um corte de cabelo mais curto, cuidar da barba e a se vestir mais seriamente, 0 que o levou a notar que "a identidade militar é, do mesmo modo que muitas outras identidades sociais, antes de tudo uma experiência corporal e estética, que se reveste de valores morais, ideológicos e culturais" (p. 193). Ao mesmo tempo, Badaró apoiou-se em três elementos para não ter que constantemente se posicionar essa lógica classificatória "amigo/inimigo", que pode às vezes representar uma armadilha: o funcionamento da hierarquia militar (sua presença era sempre justificada pela autorização do diretor do CMN, assim, questionar sua presença seria questionar o próprio diretor); a condição de estudante de doutorado na França (que Ihe conferia certo prestígio junto às patentes mais altas) e a dimensão geracional (que o aproximava dos cadetes). Para além das estratégias de posicionamento ou não nesta lógica classificatória "amigo/inimigo", Leirner observa que essa oposição está imbricada e ocupa posição central na cadeia de comando militar, sobretudo por causa da quantidade de dimensões que consegue articular, como países, exércitos, comandantes e até mesmo etnógrafos.

As mais diversas experiências apresentadas no livro confirmam que os militares, enquanto interlocutores de pesquisa, sempre posicionam de algum modo seus pesquisadores. Nesta relação que se estabelece a partir da pesquisa de campo com um objeto aparentemente fixo, mas que na realidade é negociável e contingencial, antropólogos e demais pesquisadores não apenas observam militares, suas identidades e características, mas também são observados e identificados de acordo com alguns pertencimentos (que podem também ser estrategicamente operacionalizados), tais como: "família militar", "amigo do Exército", "universitário dedicado", "espião", etc. Mas neste campo, como em poucos nos quais atua a antropologia, atentar para valores fundamentais como hierarquia, disciplina, cadeia de comando, pode influenciar positiva ou negativamente as possibilidades e os resultados das pesquisas. Assim, o livro permanece como um guia muito útil aos futuros pesquisadores do universo militar. Aliás, os organizadores do livro mostram-se confiantes de que estes virão, já que na antropologia dos militares ainda há coisas por fazer, como apontam Castro e Leirner na Apresentação do livro, "existe uma concentração muito maior de estudos sobre oficiais do que sobre praças e recrutas que cumprem o serviço militar obrigatório; sobre o Exército do que sobre a Marinha e a Aeronáutica; sobre momentos específicos da carreira do que sobre a trajetória completa da carreira militar, da formação inicial até a aposentaria" (p. 9-10).

Além de demonstrar a solidez teórica - visto que os artigos perpassam temas clássicos da antropologia, como parentesco, gênero, política e rituais - e a riqueza etnográfica desta linha de pesquisa em formação - a antropologia dos militares -, talvez a maior qualidade do livro seja a de refletir sobre algo que freqüentemente é silenciado: as trajetórias pessoais dos pesquisadores em suas tentativas e escolhas, no enfrentamento de dificuldades e na resolução de problemas que permitem a consolidação de pesquisas etnográficas ricas. A coletânea mostra como 
a reflexão metodológica e sobre as trajetórias pessoais revela elementos importantes não só de constituição da própria antropologia, mas também revela dados etnográficos centrais acerca do "objeto" e dos "nativos" com os quais os pesquisadores se relacionam, negociam e convivem, continuando o movimento que vem sendo desenvolvido desde a década de 1990, de lançar sobre os militares e suas instituições olhares não exotizantes ou externos, enriquecendo nossa compreensão sobre como se constrói a identidade militar e como se estrutura sua visão de mundo.

Aline Fonseca Iubel é mestre em Antropologia Social pela Universidade Federal do Paraná e doutoranda do Programa de Pós-Graduação em Antropologia Social da Universidade Federal de São Carlos.. 